ment of the nasal douche is rapupble, using a woak carbolic lotion, or one of common salt or carbonate of soda. The plugging of the nostrils with cotton-wool is useful in preventing the entrance of pollen and other irritating matters, but is not attogether comfortable.

I have rentured upon these fow remarks, not as containing anything novel, but with the hope that they may be of some use to others who are troubled with a very annoying and depressing complaint, for which people, as a rule, do not appear to have much sympathy. I am happy to say that my own attacks have been rather lighter each year.

\section{THE TREATMENT OF HAY-FEVER}

BX LENNOX BROWNE, F.R.C.S.ED.,

Senior Surgeon to the Central London Throat and Ear Hospital.

THE short note of Mr. W. F. Phillips, on the use of belladonna for the relief of hay-asthma, is valuable, since this remedy has, at least, the recommendation of being rational. A few further remarks in the same direction may be of interest.

It being conceded, as well established by Blackley and others, that the exciting cause of the affection is invariably irritative action of a flower-pollen on the nasal mucous membrane, possession of a peculiar idiosyncrasy as a strong predisponent must equally be admitted. It is further highly probable that this idiosyncrasy affects the subject far more locally than generally.

Now, let us consider how it is proposed to attack these causes. The most highly recommended local remedies are snuffs and insuffla tions. It is submitted, however, that they are most illogical for treatment of a membrane primarily irritated by mechanical atoms, however finely divided. The physiological use of the nostrils being to filter the inhaled atmosphere of irritant particles, it has always appeared to me as unscientific to blow powders, however sedative, into either nares or larynx in cases of disease, as to use snuffs in a state of health; the mechanical action of the powders being of itself, in my judgment, quite sufficient to contraindicate their employment. The same argument applies with even greater force to "plugging the nostrils with cotton wool or wadding." I had long had experience of the use of ointments in cases not dissimilar to those of hay-asthma, in which acute coryza is produced, or a chronic nasal catarrh is aggravated, by the dust of roads or of ball-rooms, or by certain atmospheres, as of east winds and chemical fumes; and, four or five years ago, I first recommended them to patients subject to hay-asthma, the remedy to be commenced some days, or even weeks, before the season of liability. At first, these unguents were prescribed in the form of vaseline with iodoform; but repeated objections to the odour of this last named drug, and the unsatisfactory nature of every vaunted deodorant, led me to advise that the medicated ointment should be employed only at night, pure vaseline being substituted in the day. Lately, I have come to the conclusion that the vaseline acts principally as a protective of the abnormally sensitive mucous membrane, and that the iodoform is, in very many cases, unnecessary. Consequently, I now seldom add anything beyond the oil of eucalyptus (one drachm to the ounce of vaseline), and, in severe cases, solution of atropine, B.P., in the same proportion. Let it be noted that use of the ointment, as now advised, by application of a camel's hair-brush, well charged therewith, inside the nostrils, followed by a good " sniff up," is a very different thing from a "smearing over of the upper lip and the margins of the nostrils." The use of strong smelling salts combined with carbolic acid is of service in many cases, and is weli known. It may be needful to mention that their action is quite distinctive in theory and effect from that of snuffs.

So much for local protection against an attack, or for local relief What is to be dope to eradicate local idiosyncrasy? "Whether this be due to some local abnormality affecting the structure of the mucous membrane, the capillaries, or the periphery of the nerves, of toa delicate a nature to admit of detection by available methods of research," Mackenzie says, "cannot be determined." Nor do I think it important, being content to agree with his statement that repeated examination of the interior of the nose in cases of hay-asthma will not reveal "anything more than general congestion." Such a condition is sufficiently pathological, and its treatment is easy and effectual, the indication being to change the character of the secreting mem brane. In my own practice, I prefer, as superior to all other alterant procedures, a slight searing with the galvano-cautery at only dull red, or black heat, as at once the most quick and efficient, and also the least painful remedy; but, since this method is not generally available to , many practitioners, trial may be made with one of the following remedies, as advised in order of their comparative value by $\mathrm{Dr}$. Lefferts, of New York, for the treatment of hypertrophic chronic rhinitis : fuming nitric acid, glacial acetic acid, and chromic acid. These remedies can be easily applied through an ivory nasal speculum, by means of a small probe, its end wrapped in absorbent cotton, saturated with the acid, the excess being well pressed out. Contact is maintained for barely a second... After-pain is but slight; a more or less deep slough is produced, with cicatrisation, and a less sensitive membrane is the result. . Prior to such a radical treatment, a course of inbalations of the neutral vapour of chloride of ammonium, by means of the apparatus of Burroughs or of Kerr, is often efficacious in effecting resolution, and is, moreover, of considerable service in acute attacks. Its effects may be modified or increased by the addition to the water-chamber of various medicaments, as ozonic ether, eucalyptus or pine-oil in alcohol, camphor, chloroform, or aldehyde.

It is hardly necessary to mention that any other local cause of irritation, as a relaxed uvula; enlarged veins or granulations at the back of the pharynx, or hypertrophy or polypi of nasal tissue, should be looked for, and if present should be radically treated.

So large a share of success has followed me in the line I have indicated, that $I$ have not found it necessary to search for any constitutional idiosyncrasy once the local sensibility was destroyed. Probably a gouty diathesis is the one most commonly associated with disposition to hay-fever. A few words only are necessary on my views as to the value of internal remedies for checking or allaying an acute attack.

Above everything I rely on a combination of opium and belladonna, the former of which is recommended by Dr. Mackenzie, the latter by Mr. Phillips. The first named physician, rather to my surprise, reports that he has had no experience of the use of belladonna in this complaint, and Mr. Phillips relies on this drug alone. Belladonna, from its well known action of checking, and even of suppressing, secretions from all glands, of inducing dryness of the Schneiderian membrane, and in the relief it often affords in ordinary asthma, is indicated as the most rational of all remedies for summer catarrh.

Laudanum, also, in small doses (three to six minims), given between meals, has an extraordinary effect in checking the majority of cases of common coryza. Without presuming to offer an opinion as to the correctness of the views of Dr. Harley on the non-antagonism of opium and belladonna, I may say that the idea to combine these two drugs in treatment of the complaint under consideration originated in perusal of his interesting experiments. My own experience points definitely to the conclusion that, while opium and belladonna act antagonistically in relation to prevention of some of the disagreeable physiological effects of each drug administered separately, their combination intensifies and prolongs their respective remedial actions, and on these grounds I confidently recommend their joint employment.

In conclusion, I venture to differ from the dictum that the treatment of hay-fever need by any means be considered as unsatisfactory, provided only it be conducted on scientific, not on, empirical grounds.

P.S.-Since correcting the proof of the foregoing short note, I have received from Dr. John O. Roe, of Rochester, New York, two communications to the New York Medical Society, on the Pathology and Radical Cure of Hay-Fever, in which the author brings very considerable evidence in support of the. view that in this disease there is to be found either hypertrophy of nasal tissue or some lozalised spot of sensitiveness in the nostrils. The treatment advised is that of galvanocautery, and the success is remarkable, one case having had an immunity of recurrence for five years, and others for less periods. A similar view is shared by other American specialists, notably by Dr. Daly of Pittsburgh, who has also reported several cases illustrative of the success of local treatment of theinostrils by cautery in patients subject to hay-fever.

\section{THE TREATMENT OF PHTHISIS BY MEANS OF THE EUCALYPTUS ATMOSPHERE:}

BY A. W. MAYO ROBSON, F.R.C.S. Assistant-Surgeon to the Infirmary, Leeds.

WHILST it would be presumptuous to say that a cure for phthisis has been discovered, the researches of Dr. Koch on the pathology of tubercle lead one to hope that such a desideratum is not an impossibility.

The general treatment, hygienic and otherwise, of the diathetic conditions predisposing to consumption, has been extremely successful in-preventing disease in some, and even in curing it in others; but these methods as a rule are only capable of being followed out by the rich, and even in them are not by any means always successful.

Now, if we believe that consumption is essentially tuberculous, and 
that tubercle is dependent on a bacillus, we must look for a cure in some germicide which, whilst fatal to the guest, is harmless to its host.

We know that, if we render abnormal the surroundings of organised beings, either animal or vegetable, they cease to thrive, become unhealthy, perform their functions imperfectly, and in many. cases die.

Now, one of the first functions interfered with is that of generation, as exemplified by the difficulty of getting wild animals to breed in captivity, and by the sterile condition of many plants when removed from their natural habitat.

Bacteria can be destroyed by antiseptics; and, since generation is a much higher vital act than simple growth, it is probably much easier to prevent their propagation. Hence I cannot help clinging to the hope, which is not altogether unsupported by experience, that if we can saturate the inhaled air of a phthisical patient with an antiseptic such as eucalyptol, we may hope, first, to kill the bacterium termo present in the cavities, and so prevent putrefactive deeomposition and fever; secondly, to kill the bacillus tuberculosis also present in the cavities ; and thirdly, by charging the tissues around the air-cells and around the vomicre with a substance poisonous to the organisms, to prevent the generation of fresh bacilli, and perhaps even to destroy those that have attained maturity.

Many antiseptics have been employed with more or less benefit, but the one I have for the last two years been using has given me sueh satisfactory results, that I venture to mention it with confidence, and that is the volatile oil of eucalyptus, which I order to be used in an orinasal respirator when the patient is not in the hotse ; but at home I have the chamber charged at frequent intervals with eucalyptus air, by mean's of the machine which I described fully in the BrItish Medical Journal of September 2, 1882, where I also related experiments which led to its employment. It lessens the cough, relieves the fever, and after hæmoptysis apparently prevents decomposition of the blood in the air-tubes.

Other means of relief in the way of general treatment are always carried out, so that it is difficult to say that the cure or relief is solely dependent on eucalyptus; but I firmly believe that several cases owe their cure, " apparently permanent," to this method. I will mention one case.

Mr. A., aged 26 , with a constumptive family history, consulted me for cough, expectoration, night-sweats, etc., having lost two stone in weight within thiree months. There were dulness and crepitation at both apices, with all the general symptoms of phthisis. He very carefully followed out the eucalyptus treatment for two months, and then had a sea-voyage, after which he returned quite well, and has never had the slightest relapse. Moreover, he has been able to follow his usual duties during the past year as well as formerly.

I do not wish it to be thought that all my cases have been as satisfactory as this one; but, where the eucalyptus treatment has been diligently carried out, relief has nearly always followed.

Messrs. Nayer and Meltzer manufacture the machines for the production of the antiseptic air, and; at my suggestion, they have arranged to let them out by the month to anyone wishing to give the treatment a trial.

Mr. Kingzett,drew my attention some little time ago to his valu. able antiseptic, "sanitas," which, he says, acts more strongly than eucalyptus, but in the same manner, i.e., by giving off peroxide of hydro. gen. I should think that the antiseptic air-apparatus might be advan. tageously charged with sanitas instead of eucalyptol, if the odour of the former were preferred.

Discovery of a CRematbrium. - During the progress of some excavations near Lincoln Cathedral last week, a crematorium, or cremation furnace, in a good state of preservation, was nnearthed. Near the mouth was a large quantity of charcoal, and underneath a sarcophagus. Within the latter were found ten urns of various shapes and sizes, provided with saucer-shaped covers, and all containing ashes or partly consumed bones. The discovery is one' of great interest to antiquaries, and is remarkable from the fact of the crematorium being within the limits of the old Roman city.

OVERPRESSURE IN 'ElEmentary Schools.-Dr. Crichton Browne's report on educational overpressure in elementary schools, which was presented to the Vice-President of the Committee of Council on Education some weeks ago, contains, it is understood, evidence tending to show that grave evils and serious dangers to health are involved in the system on which these schools are now conducted. Mr. Mundella has promised that the report shall be presented to Parliament, along with other papers relating to the same subject; and there ought to be no unnecessary delay in the publication of documents dealing with subject of sueh great national importance.

\section{OBSTETRIC. MEMORANDA.}

\section{NON-GRAVID HYDRORRHCEA}

THE term non-gravid hydrorrhœa I employ to designate a very anomalous copious discharge from the uterus in the unimpregnated state, and apparently allied to a similar condition occurring during gestation. Since writing my short paper (in the JourNaL of May 24th) on this subject, my attention has been called to a series of lectures by Dr. Matthews Duncan which appeared in the Medical Times and Gazette in the early part of this year. In one of these lectures more especially, he notes the occurrence of sudden gushes of fluid. One case he relates in which the so-called discharge, when collected and examined, turned out to be urine. This simply shows how necessary it is to investigate closely all cases, but more especially those in which fallacies are apt to arise; for we all may, and frequently do, come to conclusions which are perfectly unjustifiable. Dr. Duncan, however, goes on to say : "There are some sudden watery discharges which I have been unable to explain, and have tried to satisfy myself by supposing they were from the glands of Cowper." It seems to me the cases here referred to are such as those to which I apparently have been the first to draw attention, and regarding the cause and origin of which I ventured a hypothesis. The reason, most probably, why this somewhat anomalous secretion has been up to the present overlooked, is dependent upon the fact that, as a rule, all discharges in the female, unless they ctherwise attract special attention, receive the vulgar appellation "whites." Now, should my theory of the cause and origin of hydrorrhœa prove to be correct, it is quite evident that the usual line of treatment adopted by the ma ority of practitioners for the alleviation of the so-called "whites"-namely, the use of vaginal injections-will prove futile in allaying this discharge. My experience, however, of this symptom (hydrorrhœa), for symptom it undoubtedly is, has not been extensive enough to warrant me in advocating a definite line of treatment. It is one, however, without doubt, demanding general rather than local medication. JAMES Oliver, M.B.Edin.

THE APPLICATION OF THE LONG MIDWIFERY FORCEPS. THE method of introducing the upper blade of the long forceps, as advocated by Mr. Henry Cribb, in the Journal of June 14th, obviates to some extent a great difficulty. In principle, it is almost in accordance with the directions laid down in Dr. Robert Barnes's book, Lectures on Obstetrio Operations; the second edition of which I read some ten years ago. In a case which occurred in my practice about that time, I was led, or rather compelled, to adopt Dr. Barnes's instruction. The patient, a primipara 40 years of age, was in labour with twins. The abdomen was very large, and the lower extremities were odematous. To place her in the orthodox position for delivery by forceps was impossible, as she could not flex the thighs upon the abdomen sufficiently, when brought to the edge of the bed. Nor do I think the lower blade ever could have been safely introduced in the manner generally taught when I was $a$ student, owing to the great swelling of the thighs. Hence, in such a case, Mr. Cribb's modification would have proved inapplicable. I followed Dr. Barnes's direction. Holding the handle of both lower and upper blade almost at right angles to the trunk, that is, in this case, between the thighs, the blades were first directed each into the hollow of the sacrum, and then slipped, respectively, under and over the head of the child without any difficulty.

I have never since adopted any other plan ; much Jess the old ona of bringing the patient's pelvis close to the edge of the bed. Suchs proceeding is quite unnecessary, and, as Mr. Cribb has pointed out, highly inoonvenient. I have been surprised, over and over again, that, by practitioners of much wider experience than my own, this most valuable improvement upon the older method has not been adopted. I would respectfully refer Mr: Cribb, and those who may have read his interesting paper, to Dr. Barnes's book, where the modification alluded to is fully explained. S. Holgate OWen, M.D. Assistant-Physician, Manchester Clinical Hospital for Women and Children.

\section{SURGICAL MEMORANDA.}

OPERATIONS FOR HERNIA IN AGED PERSONS

Revertivg to the subject of operation for strangulated hernia in aged subjects, I may mention that. I have had four cases of this kind, three females and one male, with an aggregate age of 295 years. $\mathrm{My}$ last case occurred two months ago. The patient was a widow, 89 years of age suffering from cardiac disease and angina. She was chloroformed, novertheless, and made an excellent recovery, as did all the 